\title{
A IMPORTÂNCIA DA FORMAÇÃO DIDÁTICO-PEDAGÓGICA E A CONSTRUÇÃO DE UM NOVO PERFIL PARA DOCENTES UNIVERSITÁRIOS
}

\author{
Graziela Giusti Pachane \\ Elisabete Monteiro de Aguiar Pereira \\ Universidade Estadual de Campinas (UNICAMP), Brasil
}

\section{INTRODUÇÃO}

Quando se fala em "formação de professores", vem-nos à cabeça o processo de formação para a docência na educação básica (ensino fundamental e, no máximo, médio). Dificilmente a abordagem de formação de professores estende-se para a formação de professores universitários, como se a formação específica para o magistério nesse nível fosse algo supérfluo, ou mesmo, desnecessário.

No entanto, uma das críticas mais comuns dirigidas aos cursos superiores diz respeito à didática dos professores universitários, ou seria melhor dizer, à falta dela. Tal fato pode ser constatado tanto através da literatura específica da área, como através de conversas com alunos em diferentes tipos de instituição e em diferentes cursos.

Relatos de que o professor sabe a matéria, porém não sabe como transmiti-la ao aluno, de que não sabe como conduzir a aula, não se importa com o aluno, é distante, por vezes arrogante, ou que não se preocupa com a docência, priorizando seus trabalhos de pesquisa, são tão freqüentes que parecem fazer parte da "natureza", ou da "cultura", de qualquer instituição de ensino superior.

Ao mesmo tempo, amplia-se cada vez mais a exigência de que os professores universitários obtenham os títulos de mestre ou doutor. No entanto, é questionável se esta titulação, do modo como vem sendo realizada, possa contribuir efetivamente para a melhoria da qualidade didática no ensino superior.

Os programas de pós-graduação, de maneira geral, tendem a priorizar em suas atividades a condução de pesquisas, tornando-se responsáveis, mesmo que não intencionalmente, por reproduzir e perpetuar a crença de que para ser professor basta conhecer a fundo determinado conteúdo ou, no caso específico do ensino superior, ser um bom pesquisador.

Numa breve retrospectiva da história das universidades - de maneira geral e, mais especificamente, das brasileiras -, é possível observar que a formação exigida do professor universitário tem sido restrita ao conhecimento aprofundado da disciplina a ser ensinada, sendo este conhecimento prático (decorrente do exercício profissional) ou teórico/epistemológico (decorrente do exercício acadêmico). Pouco, ou nada, tem sido exigido em termos pedagógicos.

Acreditamos que possam existir pelo menos três fatores contribuindo para que, na cultura universitária, a tarefa de ensinar - e conseqüentemente a formação pedagógica dos professores - sejam relegadas a segundo plano.

Em primeiro lugar, a formação para a docência universitária constituiu-se historicamente como uma atividade menor. Inicialmente, havia a preocupação com o bom desempenho profissional, e o treinamento profissional, acreditava-se, poderia ser dado por qualquer um que soubesse realizar bem determinado ofício. Acreditava-se (como alguns ainda hoje acreditam) que "quem soubesse fazer, saberia 
automaticamente ensinar", não havendo preocupações mais profundas com a necessidade do preparo pedagógico do professor (MASETTO, 1998, p. 11).

Posteriormente, com a crescente aproximação das universidades do modelo humboldtiano, voltado à produção de conhecimentos, a preocupação com a formação de professores para o magistério superior centrou-se na preparação para a condução de pesquisas e, da mesma maneira, o pedagógico continuou a ser negligenciado, como se as atividades realizadas com os alunos de graduação não se configurassem como produção de conhecimento, mas, simplesmente, repetição do que já havia sido realizado por outros.

Em segundo lugar, também decorrência dessa ênfase na condução de pesquisas, os critérios de avaliação de produtividade e qualidade docente concentram-se, hoje, na produção acadêmica destes professores. Ou seja, ensino e pesquisa passam a ser atividades concorrentes, e como os critérios de avaliação premiam apenas a segunda, uma cultura de desprestígio à docência acaba sendo alimentada no meio acadêmico, comprometendo, como ressalta Pimentel (1993, p. 89), a almejada indissociabilidade ensino-pesquisa-extensão.

É possível, portanto, concluir que a prática usual nas universidades concorre para esta desvalorização do ensino, transmitindo em sua cultura valores díspares para as duas atividades (ensino e pesquisa).

Finalmente, observamos a inexistência de amparo legal que estimule a formação pedagógica dos professores universitários.

A título de exemplo, é válido mencionar que a legislação brasileira sobre educação, mais especificamente a LDB (Lei de Diretrizes e Bases da Educação Nacional) é omissa em relação à formação pedagógica do professor universitário. Num acompanhamento detalhado dos diversos momentos de discussão da LDB (cf. SAVIANI, 1998, p. 144), é possível observar-se que na proposta inicial do então senador Darcy Ribeiro, a preocupação com a formação pedagógica dos professores universitários era contemplada:

art. 74 - A preparação para o exercício do magistério superior se faz, em nível de pósgraduação, em programas de mestrado e doutorado, acompanhados da respectiva formação didático-pedagógica, inclusive de modo a capacitar o uso das modernas tecnologias do ensino.

No entanto, num processo de "enxugamento" do texto da LDB - além, é claro, das pressões feitas por diversos setores da sociedade cujos interesses podem ser contrariados com a exigência de maior capacitação docente -, omitiu-se do texto final a necessidade de formação pedagógica do professor universitário, configurando-se o texto final como segue: "Art. 66 - A preparação para o exercício do magistério superior far-se-á em nível de pós-graduação, prioritariamente em programas de mestrado e doutorado."

Assim, não encontrando amparo na legislação maior, a formação pedagógica dos professores universitários fica a cargo dos regimentos de cada instituição responsável pelo oferecimento de cursos de pós-graduação, refletindo, e ao mesmo tempo regulamentando, a crença na não necessidade de que esta formação seja oferecida. 


\section{A FORMAÇÃO DE PROFESSORES UNIVERSITÁRIOS NO CONTEXTO INTERNACIONAL}

Embora tenhamos nos centrado aqui na descrição da situação brasileira, o processo de ênfase na produção acadêmica - assim como o maior estímulo à pesquisa, em detrimento do ensino - não ocorre, apenas no Brasil, porém é um fenômeno que pode ser observado internacionalmente.

Citando um texto publicado pelo American Council on Education, no qual se lê que "o professor universitário é o único profissional de nível superior que entra para uma carreira sem que passe por qualquer julgamento de pré-requisitos em termos de competência e de experiência prévia no domínio das habilidades de sua profissão", Balzan (1997, p. 7) ressalta que:

"as afirmações acima refletem não somente preocupação com a questão da qualidade do ensino superior, como evidenciam tratar-se de um fenômeno que ultrapassa as fronteiras dos Estados, adquirindo um nível de abrangência mundial e características extremamente complexas, dadas as realidades vigentes em países situados em diferentes níveis de desenvolvimento sócio-econômico e multiplicidades de culturas construídas ao longo da história."

Marcelo García, professor da Universidade de Sevilha, menciona que na Espanha os programas de doutoramento funcionam como uma espécie de formação inicial de professores universitários no seu papel ou função de investigação. Em relação à formação pedagógica dos professores universitários, observa o panorama atual não é muito favorável, sendo que, até hoje, não existiu uma tradição de formação pedagógica, sendo que os "professores jovens sempre foram deixados sós, exceto talvez por um breve curso de iniciação" (MARCELO GARCÍA, 1999, p. 248)

Nesse mesmo sentido, Benedito, Ferrer e Ferreres (1995), num estudo bastante amplo a respeito do ensino superior na Espanha constatam que "a formação de professores universitários não tem contado, até agora, com um respaldo legislativo como ocorre com os outros níveis educativos". Salientam ainda que, ao consultar-se o Handbook of Research on Teacher Education de 1990 - a grande compilação de tudo o que ocorre na área nos EUA e em seu âmbito de influência - no intuito de buscar indícios, pesquisas, tomadas de posição sobre a formação universitária, depararam-se com uma surpresa "não encontramos nada" (p. 149).

Donald Kennedy, ex-reitor da Universidade de Stanford, publicou um livro, denominado "Academic Duty", no qual reuniu os resultados de diversas palestras ministradas a pós-graduandos, futuros professores universitários, acerca dos problemas e desafios enfrentados pelos professores universitários. Nele, enfatiza a relevância de trabalhos dessa natureza, mencionando que nos Estados Unidos, muito freqüentemente, pouca atenção é dada para as responsabilidades que os estudantes de doutorado terão futuramente com o ensino, já que eles são pressionados a finalizar sua dissertação ou a dar apoio aos programas de seus orientadores.

O autor salienta, ainda, que os professores em treinamento recebem pouca ou nenhuma preparação para a gama de desafios profissionais e pessoais que vão enfrentar como membros efetivos do corpo docente (KENNEDY, 1997, p. 30).

Tais aspectos são também apresentados por Serow (2000) ao discutir os resultados da pesquisa que conduziu nos Estados Unidos sobre a docência no ensino superior:

"um ponto de concordância entre os entrevistados era de que a pesquisa excedeu em importância

o ensino no sistema de gratificações, e que pesquisas amparadas por fundos externos e Revista Iberoamericana de Educación (ISSN: 1681-5653) 
publicações em meios apropriados se tornaram essenciais não apenas para promoção e efetivação no cargo, mas também para manter a estima aos olhos de seus pares." (p. 453)

De acordo com um dos professores entrevistados pelo autor, qualquer um que não realizasse o tipo correto e a quantidade adequada de pesquisa nunca seria aceito como um "membro de carteirinha" do corpo docente. O ensino também foi descrito por ele como tendo pouco status tanto com os chefes das faculdades como entre aqueles que administravam as universidades.

Serow esclarece que isso não significa, necessariamente, que o ensino e a orientação sejam de todo negligenciados. Ao longo de sua pesquisa, pôde constatar que o ensino representa um importante peso na avaliação docente, porém, somente quando é considerado ruim. De acordo com um professor sênior de uma faculdade de engenharia por ele entrevistado:

"Se você dá aula razoavelmente boas, isso é o que é esperado. Se não, o departamento pode usar isso contra você. (...) A ênfase mudou-se de 'quão bom professor é ele' para 'quantas queixas nós tivemos dele?' (...) Através do patrocínio de prêmios pedagógicos, bolsas para inovações didáticas e outros incentivos, a real intenção dos administradores era a de evitar ramificações de ensino ruim, através de uma diminuição das pressões de estudantes, pais, alunos recém-formados e legisladores" (SEROW, 2000, p. 453-454).

Podemos perceber, portanto, que o problema que aqui nos propomos a discutir não é isolado no Brasil. Autores que discutem a formação de professores em outros países abordam a mesma problemática, destacando não só o desprestígio do ensino em relação à pesquisa e a falta de formação de seus professores universitários, como também, enfatizando a necessidade de que tal situação seja revertida e que maior atenção seja dada à formação pedagógica do (futuro) docente do ensino superior.

\section{FORMAÇÃO PEDAGÓGICA DO PROFESSOR UNIVERSITÁRIO: UMA NECESSIDADE}

Como mencionamos, a formação do docente universitário tem se concentrado na sua crescente especialização dentro de uma área do saber. De acordo com Vasconcelos (1998, p. 86), há "pouca preocupação com o tema da formação pedagógica de mestres e doutores oriundos dos diversos cursos de pós-graduação do país. A graduação tem sido 'alimentada' por docentes titulados, porém, sem a menor competência pedagógica". Tal constatação nos leva a um questionamento acerca da correlação entre a crescente especialização oferecida pelos cursos de pós-graduação e a melhoria da qualidade docente dos professores universitários.

Marcelo García (1999, p. 244), fazendo referência a trabalhos realizados por Aparício e Felman, ressalta que, em diversas investigações, a correlação encontrada entre a produção científica dos professores e a avaliação que seus alunos fazem deles tem sido muito baixa (em torno de 0,21), concluindo as relações entre produtividade científica e eficácia docente são escassas, ou como refere Felman (1987, apud Marcelo García, 1999), são essencialmente independentes uma da outra.

A esse respeito, Pimenta e Anastasiou (2002, p. 190-196) observam que a formação aualmente oferecida aos pós-graduandos separa-os de qualquer discussão sobre o pedagógico, desconsiderando, inclusive, que os elementos-chave do processo de pesquisa (sujeitos envolvidos, tempo, conhecimento, resultados e métodos) não são os mesmos necessários à atividade de ensinar, e elaboram uma comparação entre as características dos elementos constituintes de cada atividade. 


\section{QUADRO 1}

Elementos constituintes das atividades de pesquisa e ensino, segundo Pimenta e Anastasiou (2002, p. 190-196)

\begin{tabular}{|c|c|c|}
\hline & Pesquisa & Ensino \\
\hline Sujeitos envolvidos & $\begin{array}{l}\text { Em geral o trabalho é realizado } \\
\text { individualmente; pode haver mo- } \\
\text { mentos de trabalho em grupo, mas } \\
\text { o pós -graduando, em geral, trabalha } \\
\text { apenas ligado a seu orientador. }\end{array}$ & $\begin{array}{l}\text { O professor está constantemente } \\
\text { envolvido com outros sujeitos: seus } \\
\text { pares institucionais (chefias e } \\
\text { colegas docentes), alunos, comu- } \\
\text { nidade, etc. }\end{array}$ \\
\hline Tempo & $\begin{array}{l}\text { Habitualmente é previsto em blocos, } \\
\text { conforme o projeto, e comporta al- } \\
\text { terações justificadas, submetendo- } \\
\text { se, dessa forma, a certa flexi- } \\
\text { bilidade. }\end{array}$ & $\begin{array}{l}\text { O processo de ensino em geral tem } \\
\text { de se adequar período letivo, não } \\
\text { havendo flexibilidade, constituindo- } \\
\text { se um permanente desafio a } \\
\text { adequação temporal dos cronogra- } \\
\text { mas curriculares. }\end{array}$ \\
\hline Resultados obtidos & $\begin{array}{l}\text { Os resultados dizem respeito aos } \\
\text { conhecimentos gerados sobre o } \\
\text { tema proposto após o término da } \\
\text { pesquisa, que podem levar à } \\
\text { confirmação da teoria existente ou à } \\
\text { revisão total ou parcial do refe- } \\
\text { rencial científico existente. }\end{array}$ & $\begin{array}{l}\text { O ensino deve proporcionar novas } \\
\text { elaborações e novas sínteses aos } \\
\text { professores e aos alunos, am- } \\
\text { pliando a herança cultural e pro- } \\
\text { piciando ao aluno uma apreensão } \\
\text { qualitativamente superior dos qua- } \\
\text { dros teóricos e da própria realidade. }\end{array}$ \\
\hline Conhecimentos & $\begin{array}{l}\text { Os conhecimentos constituem-se } \\
\text { em sínteses provisórias geradoras } \\
\text { de novas propostas de trabalho. }\end{array}$ & $\begin{array}{l}\text { Trata-se, em geral, do trabalho com } \\
\text { o conhecimento já existente e } \\
\text { sistematizado, a ser "apropriado" } \\
\text { pelo aluno sob a orientação do } \\
\text { professor. }\end{array}$ \\
\hline Método & $\begin{array}{l}\text { É definido ao se propor o problema, } \\
\text { tendo em vista a estreita relação } \\
\text { entre o objeto, o campo do conhe- } \\
\text { cimento e a metodologia a ser } \\
\text { trabalhada. }\end{array}$ & $\begin{array}{l}\text { Depende, inicialmente, da visão de } \\
\text { ciência, de conhecimento e de saber } \\
\text { escolar do professor. }\end{array}$ \\
\hline
\end{tabular}

Considerando as diferenças entre as atividades de pesquisar e ensinar, as autoras concluem que não seja difícil compreender por que ser um reconhecido pesquisador, produzindo acréscimos significativos aos quadros teóricos existentes, não é garantia de excelência no desempenho pedagógico e, conseqüentemente, por que os programas de pós-graduação não oferecem, necessariamente, melhoria na qualidade docente: como a pesquisa e a produção de conhecimentos são objetivos da pós-graduação, os docentes, quando participam desses programas, sistematizam e desenvolvem habilidades próprias ao método de pesquisa, deixando de lado o desenvolvimento das características necessárias para 0 desenvolvimento do ensino.

Assim, podemos perceber que os cursos de formação, quando voltados exclusivamente para a realização de pesquisas, não atendem às necessidades específicas dos professores no tocante a suas atividades de docência. Ou seja, a qualificação oferecida pelos cursos de pós-graduação, como atualmente estruturados, possibilitam aos professores a titulação, porém, a maior titulação não significa, necessariamente, melhoria na qualidade docente.

É válido ressaltar que os próprios pós-graduandos criticam o despreparo pedagógico com que iniciam seu trabalho em sala de aula, como levantado por Macedo, Paula e Torres (1998, p.1). Ainda a respeito da falta de preparo pedagógico dos futuros professores universitários, Kennedy (1997) introduz uma observação bastante interessante. Segundo o autor, a vasta maioria dos doutorados acadêmicos são 
produzidos em universidades, mas grande parte dos professores nelas formados irá lecionar em instituições de ensino superior bastante diferentes daquelas onde foram titulados. Dessa forma, "chegam ao trabalho com poucas noções sobre como realizar a transição de aprendiz experiente para professor novato, ou mesmo sobre o que é esperado deles como profissionais"(p. 30).

Embora Kennedy esteja se referindo à situação das instituições de ensino superior americanas, o que ocorre no Brasil não é diferente. Aqui, também, grande parte dos professores universitários é titulada em universidades, prioritariamente em instituições públicas (estaduais ou federais), pelas quais não serão necessariamente contratados. Assim, embora muitos professores sejam formados, ou titulados, em instituições universitárias, com tradição em pesquisa, o mercado de trabalho que para eles se abre é, muitas vezes, em instituições não-universitárias, com tradição em ensino.

Tendo em vista as recentes políticas de expansão e flexibilização do sistema de ensino superior brasileiro, essa situação de diferenciação entre instituições voltadas predominantemente ao ensino ou à pesquisa, e conseqüentemente a discrepância entre a formação oferecida ao pós-graduando e as tarefas a serem exercidas em sua futura atuação como professor, torna-se mais acentuada.

O Brasil tem vivenciado um período de diversas alterações no sistema de ensino superior, que englobam, além do crescimento destacado anteriormente, a expansão e flexibilização do sistema, mudanças na estrutura curricular (diretrizes curriculares), alterações nos critérios de ingresso nas IES, exigência de titulação do corpo docente, processos sistemáticos de avaliação, tanto em âmbito institucional como nacional, entre outros indicadores, muitos dos quais decorrentes da introdução de novas tecnologias na educação.

Esse processo, no entanto, não tem se dado de modo proporcional entre cs diferentes tipos de instituição existentes no país, havendo uma diferenciação cada vez maior entre os programas que incentivam a pesquisa e programas que priorizam o ensino (Gamboa, 1999; Saviani, 1998).

Como observado por Pimenta e Anastasiou (2002, p. 141), as oportunidades de emprego vêm aumentando com a expansão das instituições particulares de ensino em todo o território nacional, o que pode ser observado por uma análise dos dados estatísticos divulgados recentemente pelo MEC/INEP (Pachane, 2003), expansão esta que não é acompanhada de um processo de profissionalização, nem inicial nem continuada (PIMENTA e ANASTASIOU, 2002, p. 128-129).

Para as autoras, o conhecimento deste sistema é de extrema importância pois as condições de trabalho dos professores são bastante diversas entre os diferentes tipos de IES brasileiras e, dependendo do tipo de instituição ao qual o professor se vincula, um tipo de produção diferente será exigido dele, seja ela relativa a atividades de docência, de extensão ou pesquisa, cabendo lembrar que a docência estará presente em todos.

A este movimento de expansão desigual entre os diferentes tipos de IES brasileiras alia-se outro: 0 processo de flexibilização do sistema (diversificação da oferta), diferenciação que tende a se aprofundar, refletindo a adequação do sistema em face do crescimento da demanda e dos novos perfis profissionais exigidos pelo mercado. Aponta-se, hoje, para a necessidade de criação de cursos mais curtos e/ou voltados a novas especialidades, sejam elas decorrentes de abordagens interdisciplinares, do avanço da ciência e da tecnologia, da flexibilização dos campos do saber ou das necessidades criadas pelo gerenciamento de 
sistemas de novas tecnologias. Questiona-se, inclusive, qual a formação que o ensino superior deve oferecer e a quais interesses deve atender.

Paralelamente a estas mudanças, o sistema educacional tem observado um movimento no sentido de democratização do acesso ao ensino superior, como é possível de ser observado nos resultados do Censo da Educação Superior

A expansão do número de vagas, e a conseqüente ampliação do acesso ao ensino superior, proporciona uma maior heterogeneidade do público que se dirige às instituições de ensino superior. Este abre-se a parcelas da população a quem a possibilidade de graduação era, anteriormente, dificultada.

Hoje, portanto, é necessário ao professor saber lidar com uma diversidade cultural que antes não existia no ensino superior, decorrente do ingresso de um público cada vez mais heterogêneo. Um público que pode, por um lado, não estar tão bem preparado, tanto emocional quanto intelectualmente, para o ingresso no ensino superior; um público talvez mais jovem, mais imaturo, e, por vezes, pouco motivado e comprometido com sua aprendizagem, tendo em vista que o ensino superior hoje não é mais garantia de um emprego estável no futuro, mas um público que pode, por outro lado, ser muito mais exigente quanto à qualidade do curso oferecido, tendo em vista especialmente o alto grau de competitividade do mercado de trabalho (MILLAR, 1996, BRIDGES, 1995; SANTOS, 1997; RIBEIRO JÚNIOR, 2002).

Além disso, os professores passam a ter necessidade de aprender a lidar com turmas cada vez mais numerosas, pois a baixa correlação do número de alunos por professor, antes tomada como índice de qualidade de um curso, hoje passa a identificar a "ineficiência do sistema".

É necessário destacar também que o ensino superior, por muito tempo considerado ponto terminal da educação e voltado à formação profissional, tem agora para si outras funções e, dependendo do ponto de vista que adotarmos, configura-se apenas como um primeiro passo rumo a um processo de lifelong learning" (educação permanente), fenômeno que vem ocorrendo não apenas no Brasil.

Tais constatações nos levam a uma preocupação em relação à formação dos professores para atuar no ensino superior e que culminam nos questionamentos propostos por Morosini (2000, p. 11): "quem são (serão) esses novos professores? Estarão preparados didaticamente?".

Atualmente, a preocupação com a aferição da eficiência do sistema educativo, seja através do sistema nacional de avaliação ou de programas de avaliação institucional, começa a desvelar as precariedades e os pontos positivos da área e por influenciar, direta ou indiretamente, o trabalho dos professores.

Como destaca Morosini (2000, p. 13), embora o sistema nacional de avaliação não estabeleça normas de capacitação didática do docente, há uma íntima relação entre o desempenho didático do professor e o desempenho do aluno e, dessa forma, sugere que tais avaliações, mesmo não incidindo diretamente na qualidade docente, indiretamente, afetam-na.

A partir dos pontos até aqui abordados, podemos concluir que o professor universitário não se forma, hoje, para atuar necessariamente em uma universidade, porém, num complexo sistema de ensino superior, que envolve diferentes instituições e tipos de cursos. Mas, mais que isso, além de preparar-se para agir neste meio, para trabalhar com o novo perfil de alunos que chegam ao ensino superior, como também com o novo perfil exigido dos egressos do ensino superior, acreditamos que seja necessário a este 
professor conhecer esta realidade e saber entendê-la e analisá-la, ou seja, torna-se necessário que o professor desenvolva estratégias que permitam a ele refletir sobre sua docência e o contexto mais amplo no qual ela se acha inserida.

Vimos até aqui destacando o trabalho dos professores universitários em termos da docência (ensino de graduação e pós-graduação) e da realização de atividades de pesquisa (trabalho na pós-graduação, orientação de alunos, condução de pesquisas próprias, publicações, participação em encontros científicos, etc.). No entanto, não podemos reduzir as tarefas dos professores somente a estas duas dimensões. Benedito, Ferrer e Ferreres (1995) ressaltam que a própria docência tem sido vista com excessivo reducionismo ao ser identificada somente com as atividades que os professores realizam quando estão na sala de aula com seus alunos (p. 170).

Os autores apontam que as funções que fazem parte do trabalho do professor universitário são, principalmente, as seguintes: o estudo e a pesquisa; a docência, sua organização e o aperfeiçoamento de ambas; a comunicação de suas investigações; a inovação e a comunicação das inovações pedagógicas; a orientação (tutoria) e a avaliação dos alunos; a participação responsável na seleção de outros professores; a avaliação da docência e da investigação; a participação na gestão acadêmica; o estabelecimento de relações com o mundo do trabalho, da cultura etc.; a promoção de relações e intercâmbio departamental e interuniversitário, e a contribuição para criar um clima de colaboração entre os professores (BENEDITO, FERRER e FERRERES, 1995, p. 119).

Pimenta e Anastasiou (2002, p. 39), por sua vez, lembram que, para além da docência, espera-se dos professores seu envolvimento na administração e gestão em seus departamentos, na universidade, tomando decisões sobre currículos, políticas de pesquisa e financiamento, não apenas no seu âmbito, mas também no âmbito dos sistemas públicos estaduais, do sistema nacional de educação e das instituições científicas de fomento, de políticas de pesquisa, de ensino e de avaliação, aspectos que, de maneira geral, não são contemplados num processo de formação profissional do docente do ensino superior.

\section{MUDANÇAS NO MUNDO CONTEMPORÂNEO E SEU REFLEXO NO ENSINO SUPERIOR}

Até aqui, analisamos um pouco das mudanças que vêm se processando no contexto que podemos chamar de "intrínseco" ao ensino superior. No entanto, as modificações não se processam isoladamente do contexto social, político e econômico mais amplo no qual as IES se acham envolvidas.

As mudanças que vêm ocorrendo no mundo contemporâneo, assim como das mudanças nos campos das diversas ciências, inclusive da educação levam, elas também à necessidade de se repensar a formação atualmente oferecida aos futuros professores universitários e mesmo àqueles que já exercem suas funções.

Temos hoje configurado um processo de mudanças no contexto global no qual se inserem as instituições de ensino superior, mudanças relacionadas, em especial, ao avanço científico-tecnológico, a alterações na organização do trabalho (processo produtivo), à sociedade de informação, aos processos de globalização da economia e a alterações na relação dos sujeitos com o conhecimento (MORAES, 1997; RIBEIRO JÚNIOR, 2002). Tais mudanças acabam por afetar, direta ou indiretamente, a organização das IES, assim como o trabalho realizado em seu interior. 
Em complementação às alterações e aos questionamentos suscitados pelas mudanças decorrentes da "nova ordem mundial" e dos avanços tecnológicos, as instituições de ensino superior encontram-se imersas em um outro processo de mudanças, não des vinculado dos outros dois.

Como apontado por diversos autores (Santos, 1997; Kuhn, 1991; Pimentel, 1993; Cunha, 1998; Leite et al., 1998; Pereira, 2002, entre outros), vivemos um período de transição em que crenças absolutistas e de neutralidade da ciência, assim como de diversos pressupostos da modernidade, que vigoraram como verdades absolutas durante muito tempo, passam a ser questionados.

As "verdades" passam a ser vistas como sínteses provisórias, o saber é historicizado e relativizado e a divisão entre disciplinas estanques é questionada. A confiança do homem na razão é abalada e, conseqüentemente, todo o trabalho realizado dentro das instituições universitárias.

A reestruturação na forma como se concebe o saber, a influência dos aspectos tecnológicos e toda uma reestruturação na organização social clamam, portanto, por mudanças na estruturação e nos objetivos do ensino superior, eminentemente marcados pelo paradigma moderno.

Conseqüentemente, o trabalho a ser realizado pelo professor universitário sofre também alterações. Torna-se necessário ao professor pensar numa nova forma de ensinar e aprender que inclua a ousadia de "inovar as práticas de sala de aula, de trilhar caminhos inseguros, expondo-se e correndo riscos, não se apegando ao poder docente, com medo de dividi-lo com os alunos e também de desvencilhar-se da racionalidade única", pondo em ação outras habilidades que não apenas as cognitivas. Torna-se necessário, ainda, que os professores passem a pensar-se como "participantes do desvelamento do mundo e da construção de regras para viver com mais sabedoria e mais prazer" (CASTANHO, 2000, p. 87).

Não se pode mais entender o professor como "detentor do saber", nem o ensino como transmissão de um conhecimento pronto e acabado. O modelo pelo qual se pautava a organização do ensino superior não dá mais conta da complexidade do momento que vivenciamos e é constantemente impulsionado a mudanças. Neste contexto, professores e alunos passam a construir conjunta e continuamente o conhecimento, embasados nas teorias e na revisão constante destas, nos questionamentos e nas leituras da realidade e do presente histórico (PEREIRA, 2002, p. 42).

A indissociabilidade ensino-pesquisa, a perspectiva de produção de conhecimento e a autonomia de pensamento, o incentivo à criticidade e à criatividade, a flexibilização de espaços, tempos e modos de aprendizagem, a emergência da interdisciplinaridade, a necessidade de integração teoria e prática, a necessidade de separação de dicotomias (teoria/prática, forma/conteúdo entre outras), a necessidade de domínio de novas habilidades decorrentes de avanços tecnológicos (como uso de realidade virtual), o resgate da ética, a incorporação da afetividade, a ênfase ao posicionamento político do professor e a centralização do processo educativo na aprendizagem do aluno, entre outros fatores que aqui poderíamos enumerar, alteram profundamente o perfil necessário ao professor numa instituição de ensino superior e nos chamam a atenção para a necessidade de que estes professores, ou futuros professores, estejam conscientes desses processos nos quais se acham envolvidos.

Percebemos, portanto, que as características necessárias aos professores universitários hoje, extrapolam - e muito - os limites do conhecimento aprofundado da matéria de sua especialização e a aquisição de habilidades necessárias à condução de pesquisas, e seguem-se a dimensões muito mais 
amplas, que nos levam a argumentar em favor da importância da formação pedagógica do professor universitário.

\section{CONSIDERAÇÕES FINAIS}

Ao longo do texto, apresentamos alguns aspectos que, em nossa opinião, influenciam a ampliação do consenso quanto à importância da formação pedagógica do professor universitário e justificam a necessidade de que esta formação seja tomada de forma mais efetiva.

Entre estes aspectos, destacamos: 1) expansão do ensino superior; 2) diversificação do sistema de ensino superior; 3) instituição de um Estado Avaliativo; 4) mudança do perfil do aluno ingressante no ensino superior; 5) mudança no perfil esperado do egresso do ensino superior (e conseqüentemente do papel a ser desempenhado por estas instituições e seus professores); 6) mudanças no paradigma científico e pedagógico; 7) crescente percepção/conscientização dos próprios docentes a respeito da necessidade de formação para a atuação como professores no ensino superior; 8) emergência de um novo perfil de professor universitário, o que poderá se refletir na exigência de sua formação pedagógica e 9) a baixa correlação entre a formação atualmente oferecida em cursos de pós-graduação e a melhoria da qualificação do professor para o exercício da docência no ensino superior.

Ao considerarmos todos os dados apresentados no presente capítulo em conjunto com as críticas dirigidas à falta de didática dos docentes universitários, como apresentada em diversos estudos (Balzan, 1988; Cunha, 1989; Comvest, 1996; Masetto, 1998; Pachane, 1998; Leite et al., 1998, entre outros), podemos concluir que o panorama do ensino superior hoje aponta, cada vez mais, para a necessidade de formação pedagógica de seus professores, podendo até vir a se constituir numa exigência $\infty$ sistema educacional.

Tendo em conta que a visão da preparação para a docência no ensino superior como algo desnecessário vem se constituindo historicamente e que os critérios de avaliação docente têm se concentrado na produtividade acadêmica, a tentativa de promover a valorização da atividade docente e do ensino de graduação, e conseqüentemente da formação pedagógica do professor universitário, a nosso ver, necessita passar pela mudança na cultura acadêmica, que atribui valores díspares a cada uma das atividades constituintes do fazer universitário.

Dessa maneira, a valorização do ensino e da formação pedagógica do professor universitário demandaria, em primeiro lugar, a alteração do modo como as questões pedagógicas são entendidas e tratadas na universidade, superando a crença de que para ser bom professor basta conhecer profundamente e conseguir transmitir com clareza determinado conteúdo, ou, no caso mais específico do ensino superior, ser um bom pesquisador.

Como concluem Benedito, Ferrer e Ferreres (1995) as exigências que neste momento se colocam ante o desenvolvimento das novas titulações e a implantação de planos de estudo modernos, flexíveis e relacionados com o mundo do trabalho, assim como o fato de que a profissão docente se exercita em um contexto espaço-temporal determinado, com umas pessoas determinadas, que exigem uma adaptação particular àquelas condições e características pelas quais é necessário preparar o docente, constituem-se em razões mais que suficientes para considerar que "a docência universitária é importante e a formação de seus profissionais já não admite demora" (p. 186-187). 


\section{REFERÊNCIAS BIBLIOGRÁFICAS}

BALzAN, Newton César. A didática e a questão da qualidade do ensino superior. Cadernos Cedes (22). São Paulo: Cortez, 1988.

. Do Estudante ao Professor Universitário: caminhos para a didática do ensino superior. Revista de Educação, 1997, v. 1, n. 3, 7-24 (Trabalho apresentado no $9^{\circ}$ Congresso Mundial de Educação Comparada em Sydney - Austrália, julho 1996).

Benedito, A. V, FERRER, V E FeRRERES, V. La Formación Universitária a Debate. Barcelona, Publicaciones Universitat de Barcelona, 1995.

BRASIL. Lei n. 9.394/96 de 20 de dezembro de 1996. Lei de Diretrizes e Bases da Educação Nacional. Diário Oficial da República Federativa do Brasil, Brasília, DF, no. 248, dez. 1996, p. 27.833-27.841.

BRIDGES, William. Um mundo sem empregos - Jobshift: os desafios da sociedade pós-industrial. São Paulo: Makron Books, 1995.

CASTANHO, Maria Eugênia. A criatividade na sala de aula universitária. In: VEIGA, IIma Passos, CASTANHO, Maria Eugênia. (org.) Pedagogia Universitária: a aula em foco. Campinas, SP: Papirus, 2000.

COMVEST. Relatório de Avaliação PAEG-1996. Campinas-SP: Unicamp: Coordenação de Pesquisa Comvest, 1996.

CUNHA, Maria Isabel da. O bom professor e sua prática. Campinas, SP: Papirus, 1989. O professor universitário na transição de paradigmas. Araraquara: J.M. Editora, 1998 (a).

GAMBOA, Sílvio. A pesquisa na construção da universidade: compromisso com a aldeia num mundo globalizado. In: LOMBARDI, José Claudinei (org.). Pesquisa em Educação. Campinas, SP: Autores associados: HISTEDBR: Caçador, SC, UnC, 1999, p. 77-91.

KENNEDY, Donald. Academic Duty. Cambridge, EUA, Londres, Inglaterra: Harvard University Press, 1997. KUHN, Thomas. Das Estruturas das Revoluções Científicas. São Paulo: Perspectiva, 1991.

LEITE, Denise et al. A avaliação institucional e os desafios da formação do docente na universidade pósmoderna. In: MASETTO, Marcos (org.). Docência na Universidade. Campinas, SP: Papirus, 1998. p. 39-56.

MACEDO, D. V., E. PAULA, B. B. TORRES. Formação pedagógica dos estudantes de pós-graduação. Campinas: Unicamp: São Paulo: USP, 1998. (Trabalho não publicado).

MARCELO GARCíA, Carlos. Formação de Professores: para uma mudança educativa. Porto, Portugal: Porto Ed., 1999 (edição original Formación del Profesorado para el cambio educativo, Barcelona, Espanha: EUB, S. L., 1995).

MASETTO, Marcos (org.). Docência na Universidade. Campinas, SP: Papirus, 1998. . Professor universitário: um profissional da educação na atividade docente. In: MASETTO, M. (org.). Docência na Universidade. Campinas, SP: Papirus, 1998. p. 9-26 
MENGES, Robert J.; WEIMER, Maryellen (ed.). Teaching on solid ground: using scholarship to improve practice. San Francisco-EUA: Jossey-Bass, 1996.

MILLAR, Susan. B. New roles for teachers in today's classrooms. In: Teaching on solid ground: using scholarship to improve practice. San Francisco-EUA: Jossey-Bass, 1996. p. 155-178.

MORAES, Maria Cândida. O Paradigma Educacional Emergente. Campinas, SP: Papirus, 1997. (Coleção Práxis).

MORAES, Sílvia. Currículo, Transversalidade e Pós-Modernidade. In: SANTOS FILHO, Camilo; MORAES, Silvia (org.). Escola e universidade na pós modernidade. Campinas: Mercado de Letras; São Paulo: Fapesp, 2000. p. 201-247.

MOROSINI, Marília Costa. Docência Universitária e os desafios da realidade nacional. Professor do Ensino Superior - Identidade, docência e formação. Brasília: Inep/MEC, 2000. p. 11-20.

PACHANE, Graziela Giusti. A universidade vivida: a experiência universitária e sua contribuição ao desenvolvimento pessoal a partir da percepção do aluno. 1998. 196 f. Dissertação (Mestrado em Educação) - Faculdade de Educação, Unicamp, Campinas.

. A Importância da Formação Pedagógica para o Professor Universitário: a experiência da Unicamp. 2003. 255f. Tese (Doutorado em Educação) - Faculdade de Educação, Unicamp, Campinas.

PEREIRA, Elisabete M. de Aguiar. Implicações da Pós-modernidade para a Universidade. Avaliação. Ano 7. v. 7 , n. 1 , mar. 2002. p. $35-46$.

PIMENTA, Selma Garrido; ANASTASIOU, Léa das Graças Camargos. Docência no Ensino Superior. São Paulo: Cortez, 2002. (coleção Docência em Formação v. 1).

PIMENTEL, Maria da Glória. O professor em construção. Campinas, SP: Papirus,1993.

RIBEIRO JÚNIOR, João. Globalização, Mercado de Trabalho e Educação. Limeira: Instituto Superior de Ciências Aplicadas, 2002 (trabalho não publicado).

SANTOS FILHO, Camilo; MORAES, Silvia (org.). Escola e universidade na pós - modernidade. Campinas: Mercado de Letras; São Paulo: Fapesp, 2000.

SANTOS, Boaventura de Souza. Pela mão de Alice - o social e o político na pós-modernidade. 3. ed. São Paulo: Cortez, 1997 (Edição Portuguesa: Porto: Afrontamento, 1994).

SAVIANI, Dermeval. A nova lei da educação: trajetória, limites e perspectivas. $4^{\mathrm{a}}$ ed. Campinas-SP: Autores Associados, 1998.

SEROW, Robert C. Research and teaching at a research university. Higher Education v. 40. n. 4. December 2000. Reino Unido: Klwer Academic Publishers. p. 449-463.

VASCONCELOS, Maria Lúcia M. Carvalho. Contribuindo para a formação de professores universitários: relatos de experiências. In: MASETTO, Marcos (org.). Docência na Universidade. Campinas, SP: Papirus, 1998. p. 77-94.

VEIGA, IIma Passos, CASTANHO, Maria Eugênia (org.). Pedagogia Universitária: a aula em foco. Campinas, SP: Papirus, 2000. 


\title{
Contactar
}

Revista lberoamericana de Educación

\author{
Principal OEI
}

